\title{
Female sterilization failure, consequences and further contraception: a review of cases over ten years
}

\author{
Reena Rani $^{1 *}$, Rachna Sharma ${ }^{1}$, Charu Kohli $^{2}$
}

\begin{abstract}
${ }^{1}$ Department of Obstetrics and Gynecology, Maulana Azad Medical College and Lok Nayak Hospital, Delhi, India ${ }^{2}$ Department of Community Medicine, ESIC Medical College and hospital, Faridabad, Haryana, India
\end{abstract}

Received: 30 June 2020

Revised: 19 August 2020

Accepted: 03 September 2020

\author{
*Correspondence: \\ Dr. Reena Rani, \\ E-mail: dr.reena0310@gmail.com
}

Copyright: (c) the author(s), publisher and licensee Medip Academy. This is an open-access article distributed under the terms of the Creative Commons Attribution Non-Commercial License, which permits unrestricted non-commercial use, distribution, and reproduction in any medium, provided the original work is properly cited.

\section{ABSTRACT}

Objective: To study the socio-demographic profile and etiological factors responsible for failure of tubal ligation. Their outcome and further adopted methods of contraception.

Methods: This was a retrospective observational study done in a tertiary care centre from January 2009 to December 2018. All cases who came with sterilization failure were reviewed including their demographic patterns, previous methods used and the contraception choices adopted after procedural failure.

Results: Over a period of ten years, out of a total of 157 cases of sterilization failure $43.33 \%(n=68)$ were laparoscopic interval ligation, $42.60 \%(n=67)$ were laparoscopic ligation with termination of pregnancy, $10.20 \%(n=16)$ were sterilization done along with lower segment cesarean section and $1.9 \%(n=3)$ were mini-laparotomy (minilap) done in postpartum period. Only $63.05 \%(n=99)$ got repeat sterilization procedure done despite previous failure. Out of 157 cases, in $50.9 \%(\mathrm{n}=80)$ recanalization was found, tuboperitoneal fistula was responsible in $5.7 \%(\mathrm{n}=9)$ women, slipped fallope ring was found in $5.7 \%(\mathrm{n}=9)$ women, wrong application of fallope ring was seen in $1.9 \%(\mathrm{n}=3)$ and $35.6 \%$ $(\mathrm{n}=56)$ did not opted for religation.

Conclusion: Failures of sterilization procedures do exist especially in laparoscopic ligation. Counseling prior to adoption of this method, risk of failure and other noninvasive options of contraception must be discussed.

Keywords: Contraception, Fertility control, Laparoscopy, Sterilization failure

\section{INTRODUCTION}

Population explosion is a new crisis which developing countries like India are facing now a days. Promoting contraception among reproductive age group is the only way to overcome this crisis. Among various types of contraceptive choices, female sterilization is the most popular permanent method of pregnancy prevention worldwide. The procedure is commonly performed on healthy women at their request. Either tubal occlusion via application of mechanical device (clip or fallope ring) or tubal excision and separation can be used to achieve female sterilization depending upon the available resources. Laparoscopic sterilization using the Filshie clip is the principal method in Europe, Canada and Australia. Laparoscoic tubal ligation using fallope ring is among most common female sterilization method in India. Each year in USA, around 3,45,000 women undergo sterilization procedures and a total 10.3 million women rely on female sterilization for pregnancy control. ${ }^{1,2}$

Despite being a highly effective method of female sterilization, failure are known to occur in 1 in 200 cases. $^{3}$ Various reasons has been documented which are responsible for sterilization failure. This could be due to variation in: surgeon experience, place where procedure 
carried out, method chosen, women characteristics undergoing sterilization and at what time of reproductive cycle it was carried out. Author, in this study tried to identify the demographic profile and etiological factors which could be responsible for the procedure failure so as to reduce the sterilization failure in future via controlling the modifiable factors if present.

Sterilization procedure is a major decision taken by any individual. Losing faith on effectiveness of an invasive method of contraception, availability of other non-invasive choices with similar efficacy and relief from post sterilization regret are important in deciding future contraception post procedure failure factors. This trend of post sterilization failure contraceptive choices among the cases have also been highlighted in this study.

\section{METHODS}

This is a retrospective observational study performed in the Department of Obstetrics and Gynecology, Maulana Azad Medical College and associated hospitals, New Delhi. It included collection and reviewing of data of cases presenting with sterilization failure over the time period of January 2009 to December 2018. The cases included in the study were either follow up from same centre or referred from the nearby areas. The data involve subjects demographic details (age, parity), place and time of sterilization, sterilization failure interval, gestational age at which failure was reported, further contraception decision, intraoperative finding in cases where resterilizations was done, were collected. Luteal phase pregnancies were not included in the data.

\section{RESULTS}

Over ten year of duration from January 2009 to December 2018, a total of 157 cases of sterilization failure were identified. Table 1 demonstrates the distribution of age group of cases. Women of age group less than 30 years constituted the largest group. Majority of women belonged to parity of 3 (Table 2). When different methods of female sterilization were compared (Table 3), laparoscopic interval tubal ligation accounted for $43.33 \%$ of sterilization failure followed by laparoscopic ligation done along with termination of pregnancy $42.75 \%$ while the rates of failure noticed less in mini-laparotomy or those done with caesarean section. The longest interval documented between sterilization procedure and failure was 13 years. (Table 4) sterilisation failure occurring within 1 year accounted for $41.30 \%$ of cases while those occurring $>10$ years onwards were just $1.27 \%(n=2)$. A total of 135 cases $(85.98 \%)$ were follow-up from our institute and rest done in rural area. One case of ectopic pregnancy was documented for which laparotomy and salpingectomy was done; rest were intrauterine pregnancy. First trimester intrauterine pregnancy was $83.43 \%$ $(n=131), 14.01 \%(n=22)$ were detected in second trimester, while four of the cases presented in third trimester. Out of $157,29.7 \%(n=41)$ preferred to continue the pregnancy without any future sterilization procedure, while rest got termination of pregnancy done (Table 5).

Table 1: Age distribution.

\begin{tabular}{|l|l|}
\hline Age (years) & Number of cases (n) \\
\hline Less than 30 & 75 \\
\hline $\mathbf{3 0 - 3 5}$ & 72 \\
\hline More than 35 & 10 \\
\hline
\end{tabular}

Table 2: Parity.

\begin{tabular}{|ll|}
\hline Parity (P) & Number of cases (n) \\
\hline$\leq \mathbf{2}$ & 45 \\
\hline $\mathbf{3}$ & 74 \\
\hline $\mathbf{4}$ & 27 \\
\hline $\mathbf{2}$ & 11 \\
\hline
\end{tabular}

Table 3: Failed sterilization methods.

\begin{tabular}{|ll|}
\hline Failed sterilization methods & $\begin{array}{l}\text { Number of cases } \\
(\%)\end{array}$ \\
\hline $\begin{array}{l}\text { Interval laparoscopic } \\
\text { ligation }\end{array}$ & 68 \\
\hline Postabortal ligation & 67 \\
\hline Minilap ligation & 6 \\
\hline Along with cesarean section & 16 \\
\hline
\end{tabular}

Table 4: Failure detection period since main procedure.

\begin{tabular}{|lll|}
\hline Time (years) & Number & Percentage \\
\hline$<\mathbf{1}$ & 60 & 38.2 \\
\hline $\mathbf{1 - 5}$ & 82 & 52.2 \\
\hline $\mathbf{5 . 1 - 1 0}$ & 13 & 8.2 \\
\hline$>\mathbf{1 0}$ & 2 & 1.2 \\
\hline Total & 157 & 100 \\
\hline
\end{tabular}

Table 5: Method opted after diagnosis of ligation failure.

\begin{tabular}{|lll|}
\hline Opted decision & Number & Percentage \\
\hline $\begin{array}{l}\text { Continued pregnancy } \\
\text { without ligation }\end{array}$ & 41 & 26.1 \\
\hline $\begin{array}{l}\text { Continued pregnancy } \\
\text { followed by ligation }\end{array}$ & 3 & 1.9 \\
\hline MTP without ligation & 3 & 1.9 \\
\hline MTP with ligation & 96 & 61.1 \\
\hline MTP with IUCD insertion & 9 & 5.7 \\
\hline $\begin{array}{l}\text { Laparotomy followed by } \\
\text { salpingectomy }\end{array}$ & 2 & 1.2 \\
\hline Lost to follow up & 3 & 1.9 \\
\hline Total & 157 & 100 \\
\hline
\end{tabular}

Resterilization was done in $63.05 \%(n=99)$ of cases. As per our institute protocol resterilization were done by minilaparotomy and the cut segments of fallopian tube were 
sent for histopathological examination and ligation certificate was issued after pathology report. Six patients opted for $\mathrm{Cu}$ - $\mathrm{T}$ Intrauterine contraceptive device. Reasons for sterilization failure were reviewed in patients who consented for religation. The various causations have been described in (Table 6).

Table 6: Intraoperative finding.

\begin{tabular}{|lll|}
\hline $\begin{array}{l}\text { Reasons for ligation } \\
\text { failure }\end{array}$ & Number & Percentage \\
\hline $\begin{array}{l}\text { Wrong placement of } \\
\text { fallope ring }\end{array}$ & 3 & 1.9 \\
\hline Slipped fallope ring & 9 & 5.7 \\
\hline Tuboperitoneal fistula & 9 & 5.7 \\
\hline $\begin{array}{l}\text { Spontaneous } \\
\text { recanalization }\end{array}$ & 80 & 50.9 \\
\hline $\begin{array}{l}\text { Cause not known } \\
\text { (religation not done, lost } \\
\text { to follow up) }\end{array}$ & 56 & 35.6 \\
\hline
\end{tabular}

\section{DISCUSSION}

Female sterilization is a well-known effective method of permanent sterilization but not a perfect method without any failures. It is performed in a nonpregnant state in early proliferative phase of reproductive cycle after ruling out any suspicion of pregnancy. If there is any doubt in the particular cycle then it should be explained to the patient and procedure is postponed for next cycle to avoid any risk of failure. Most of these sterilizations are done as interval procedure (6 weeks after pregnancy). While, this procedure can be performed in the postpartum period also (combined with caesarean section or via mini laparotomy) or post-abortion. However, this period is associated with higher rates of failure and regret by the woman and this should be incorporated into the counselling and documentation prior to the procedure. ${ }^{4,5}$ Counselling especially regarding permanent nature of this procedure but still small chance of failure must be clearly informed to the patient.

Sterilization failure rates are calculated as pearl index (failure rates per 100 women years). It depends on a variety of direct and indirect factors. However exact cause and prediction of future failure is still lacking. It is especially important to discuss these factors responsible for failure in order to develop strategies which are to reduce future failure and in this era of huge legitimacy, to differentiate the negligent cases from non-negligent one.

In this study failure chances were found higher in young age group ( $<30$ years) and multiparous women which is similar to that found in study by Peterson et al and Trusell et al. ${ }^{6,7}$ It has been hypothesized by Varma et al that time interval since surgery to failure could predict the etiology for failure. ${ }^{8}$ According to their study this interval period of less than 9 months was seen in wrongly done procedures, while this interval more than 9 months was associated with spontaneous of recanalization and not associated with negligence. ${ }^{8}$ In our study $36.3 \%(n=57)$ were failure seen in interval $\leq 9$ months from the sterilization procedure, while wrong application of fallopian tube was found in $1.9 \%(n=3)$ women. Maximum interval period from procedure to failure was 13 years seen in one patient in whom interval laparoscopic ligation was done in our institute. As compared to similar study where $<1$ year interval was seen in $15 \%$ of cases and the maximal interval was 20 years. ${ }^{9}$

In our study $29.7 \%$ patient continued their pregnancy without any future sterilization. This could be explained via the fact that that tubal occlusion could be associated with either the feeling of regret post sterilization or lack of faith in invasive permanent method after failure. The American College of Obstetricians and Gynecologists (ACOG) suggests that the incidence of regret following tubal occlusion is between $0.9 \%$ and $26 \% .^{10}$ A number of studies have reported that the incidence of regret and dissatisfaction is increased when sterilization has been performed concomitantly with caesarean section, particularly if women have felt pressured into the decision by a health professional. ${ }^{11,12}$ In our study out of all who continued with pregnancy without future sterilization $59 \%$, got tubal occlusion done along with preceding pregnancy event. This further emphasizes the need for proper counselling and written informed consent where sterilization is requested in association with any pregnancy related event.

The psychological and physical morbidity following failed sterilization often leads to litigation. ${ }^{13}$ Hence here comes the role of written informed consent and regular drills for teaching sterilization skills to operating surgeons. As these are the only two ways to handle these litigations in future. Permanent nature of sterilization procedure, its alternative, risk, benefits and the feeling of regret in future must be discussed with women before heading towards the procedure directly.

\section{CONCLUSION}

Female sterilization is a widely accepted method as permanent method of contraception with minimal failure rate but this minimal chance of failure must be discussed with the women. Local hospital protocols must be fulfilled for every woman undergoing permanent sterilization.

Funding: No funding sources

Conflict of interest: None declared

Ethical approval: The study was approved by the Institutional Ethics Committee

\section{REFERENCES}

1. Jones J, Mosher W, Daniels K. Current contraceptive use in the UnitedStates, 2006-2010, and changes in patterns of use since 1995. NatlHealth Stat Rep. 2012;60:1-5. 
2. Mosher WD, Jones J. Use of contraception in the United States: 1982-2008. Vital Health Stat. 23 2010:1-4.

3. Royal College of Obstetricians and Gynaecologists. Male and Female Sterilisation. London: RCOG Press, 2004.

4. Chi IC, Siemens AJ, Champion CB, Gates D, Cilenti D. Pregnancy following minilaparotomy tubal sterilization-an update of an international data set. Contraception. 1987;35(2):171-8.

5. Hillis SD, Marchbanks PA, Tylor LR, Peterson HB. Post-sterilization regret: findings from the United States Collaborative Review of Sterilization. Obstet Gynecol. 1999;93(6):889-95.

6. Peterson HB, Xia Z, Hughes JM, Wilcox LS, Tylor LR, Trussell J. The risk of pregnancy after tubal sterilization: findings from the U.S. collaborative review of sterilization. Am J Obstet Gynecol. 1996;174(4):1161-8.

7. Trussell J, Guilbert E, Hedley A. Sterilization failure, sterilization reversal, and pregnancy after sterilization reversal in Quebec. Obstet Gynecol. 2003;101(4):677-84.
8. Varma R, Gupta JK. Failed sterilisation: Evidence-based review and medico-legal ramifications. BJOG 2004;111:1322-32.

9. Date SV, Rokade J, Mule V, Dandapannavar S. Female sterilization failure: Review over a decade and its clinicopathological correlation. Int $\mathbf{J}$ App Basic Med Res. 2014;4:81-5.

10. ACOG Practice Bulletin No. 46, September 2003 (replaces Technical Bulletin Number 222, April 1996). Int J Gynaecol Obstet. 2003;83:339-50.

11. Emens JM, Olive JE. Timing of female sterilisation. BMJ 1978;2(6145):1126.

12. Wilcox LS, Chu SY, Eaker ED, Zeger SL, Peterson HB. Risk factors for regret after tubal sterilization:5 years of follow-up in a prospective study. FertilSteril 1991;55:927-33.

13. Argent V. Failed sterilization and the law. Br J Obstet Gynaecol. 1988;95(2):113-5.

Cite this article as: Rani R, Sharma R, Kohli C. Female sterilization failure, consequences and further contraception: a review of cases over ten years. Int $\mathbf{J}$ Reprod Contracept Obstet Gynecol 2020;9:4032-5. 